\title{
STABILITY OF ANTIMICROBIAL ACTIVITY OF PULLULAN EDIBLE FILMS INCORPORATED WITH NANOPARTICLES AND ESSENTIAL OILS AND THEIR IMPACT ON TURKEY DELI MEAT QUALITY \\ Khalaf, H.H.; Sharoba, A.M.; El-Tanahi, H.H. and Morsy, M.K. * ${ }^{1}$ Department of Food Science, Faculty of Agriculture, Benha University, Egypt *Corresponding author:Mohamed Khairy Morsy, Food Science Department, Faculty of Agriculture, Benha University, Qaluobia, Egypt. Tel.: +2 012 23831825; fax: +2 0132467786. \\ E-mail address: mohamed.abdelhafez@fagr.bu.edu.eg, drkhairy3000@yahoo.com
}

\begin{abstract}
Edible films containing antimicrobials are gaining importance as potential treatment to extend product shelf life and reduce risk of pathogens. Antimicrobial activities of pullulan films incorporated silver nanoparticles (Ag NPs) $100 \mathrm{~nm}$, zinc oxide nanoparticles (ZnO NPs) $110 \mathrm{~nm}$, oregano oil (OR) $2 \%$ and rosemary oil (RO) $2 \%$, against Listeria monocytogenes and Staphylococcus aureus, were evaluated during the preparation and storage at $4,25,37$, and $55^{\circ} \mathrm{C}$ up to 49 days in plate overlay assays (in vitro). Moreover, the prior pullulan films were applied directly on turkey deli meat were inoculated by L.monocytogenes and $S$. aureus and stored at 4 ${ }^{\circ} \mathrm{C}$ for two weeks. The results from this study demonstrate that Ag NPs and OR edible films more active than ZnO NPs and RO, respectively. The optimum conditions for storage pullulan edible films incorporated nanoparticles (NPs) and/or essential oils (EOs) were 4 and $25^{\circ} \mathrm{C}$. Ag NPs, ZnO NPs, OR, and RO based films were exhibited significant effects as antibacterial activity against pathogens. These results revealed that (NPs) and/or (EOs) have a good potential to be incorporated into pullulan to make an antimicrobial edible film or coating for various food applications.

Keywords: nanotechnology, antibacterial activity, oregano, rosemary, silver nanoparticles, zinc oxide nanoparticles, pullulan, edible film, physical properties, storage stability.
\end{abstract}

\section{INTRODUCTION}

In recent years, antimicrobial packaging has attracted much attention from the food industry to the increase in consumer demand for minimally processed and preservative-free products. Use of antimicrobial substances based on nanoparticles and essential oils are of great importance and can control the microbial population and target specific microorganisms to provide higher safety and quality products (Appendini and Hotchkis 2002). These packaging technologies could play a role in extending shelf-life of foods and reduce the risk from pathogens. Antimicrobial packaging is a promising form of active food packaging, in particular for meat products. Since microbial contamination of these foods occurs primarily on the surface, due to postprocessing handling, attempts have been made to improve safety and to delay spoilage by use of antibacterial sprays or dips (Quintavalla and Vicini 2002). 
Active packaging is an innovative concept in which the package, the product, and the environment interact to prolong the shelf-life, or to enhance safety or sensory properties, while maintaining the quality of the product (Marcos et al. 2013). These biodegradable polymeric films offer alternative packaging options with no contribution to the environmental pollution while being obtained from renewable sources with low cost (Tharanathan 2003; Lu et al. 2005). The antimicrobial properties of silver nanoparticles (Ag NPs), for example, have been increasingly exploited in consumer products such as food packaging, deodorants and bandages (Chen and Schluesener 2008; Kumari et al. 2010) as antimicrobial agents in food contact material (Suppakul et al. 2003; Damm et al. 2008). It has been reported that some antimicrobial agents may affect the physical properties, processability or machinability of the packaging material. As several recent reports, ZnO nanoparticles (ZnO NPs) have demonstrated fair antimicrobial activity (Yadav et al. 2006) and it has been shown on the basis of preliminary growth analysis, that $\mathrm{ZnO}$ nanoparticles have higher antibacterial effects on microorganism like $S$. aureus than any other metal oxide nanoparticles (Jones et al. 2007; Nafchi et al. 2013). Also, essential oils from herbs and spices have been known to exhibit antimicrobial properties. Numerous of essential oils have shown antimicrobial activity in vitro against different food-borne pathogens such as $E$. coli, C. jejuni, S. enterica, and L. monocytogenes (Friedman et al. 2002; Olasupo et al. 2003). Extracts of clove and thymol were effective against $S$. Typhimurium and E. coli O157:H7 on fresh lettuce and fruits (Kim et al. 2011; Gniewosz and Synowiec 2011).

Pullulan is an extracellular polysaccharide produced by the fungal organism, Aureobasidium pullulans. (Diab et al. 2001; Cheng et al. 2011) showed that the resulting films are colorless, tasteless, resistant to oil and exhibit very low oxygen permeabilities and appropriate barrier properties. This microbial polysaccharide has not been largely exploited as a packaging material, except in some applications to prevent rancidity. (Kandemir et al. 2005) demonstrated that pullulan film exhibited antimicrobial activity against E. coli by introducing partly purified lysozyme to a solution of pullulan. Trinetta et al. (2010) demonstrated the effectiveness of sakacin A-containing pullulan film to control the growth of $L$. monocytogenes and the applicability of active pullulan films in delivering a bacteriocin directly to a food surface.

Properties of edible films and coatings generally vary with storage time due to the intrinsic instability of their raw materials. These variations could affect their functionality on foods; therefore, stable properties of films are generally required (Oses et al. 2009). When films or coatings are exposed to certain environmental conditions, antimicrobial activity, physical and chemical changes may take place during storage. Chemical changes such as oxidation of sulfhydryl groups were reported to cause the degradation of protein polymeric chains in wheat gluten film (Micard et al. 2000). It is also reported that physical changes such as the migration of low molecular weight plasticizers cause lower flexibility in whey protein films (Anker et al. 2001).

The objective of this work was to study of physical properties of pullulan films. 
Also, the effects of storage temperature on antimicrobial activity of nanoparticles and essential oils-containing pullulan edible films against pathogenic microorganisms were investigated. Moreover, the effectiveness of pullulan films to control the growth of the pathogen in turkey deli meat was evaluated.

\section{MATERIALS AND METHODS}

\section{Bacterial strains:}

Two bacterial strains used in the present study were Staphylococcus aureus (11988 American Type Culture Collection [ATCC]; Manassas, VA, USA), and Listeria monocytogenes (ATCC 94229). The strains were maintained on Tryptic Soy Agar (Difco Laboratories, Spark, MD) plates at 37 ${ }^{\circ} \mathrm{C}$ for $24 \mathrm{~h}$ and stored at $4^{\circ} \mathrm{C}$. Cultures were propagated twice in Tryptic Soy Broth (Difco Laboratories) and incubated for $16 \mathrm{~h}$ at $37^{\circ} \mathrm{C}$ before use in subsequent experiments.

Antimicrobials:

Food grade essential oils (EOs) of oregano (Origanum minutiflorum) and rosemary (Rosmarinus officinalis L.) were purchased from (Sigma Aldrich Company, USA). Aqueous silver nanoparticles dispersion (Ag NPs) with diameter $100 \mathrm{~nm}$, and zinc oxide nanoparticles dispersion (ZnO NPs) with diameter $110 \mathrm{~nm}$, were purchased from (Sigma Aldrich Company, USA).

\section{Pullulan film formation:}

Pullulan (Pul) was supplied by Hayashibara Company (Okayama, Japan). Glycerin (Gly) was obtained from the VWR Company (Batavia IL, USA); xanthan gum (Xa) was purchased from TCl America (Portland OR, USA), and locust bean (Lb) from CP Kelco (Lille Skensved, Denmark).

Pullulan $(5 \% \mathrm{w} / \mathrm{v})$ was dissolved in distilled water with a temperature of $80^{\circ} \mathrm{C} \pm 1^{\circ} \mathrm{C}$. Glycerol was added $(1.5 \% \mathrm{w} / \mathrm{v})$, xanthan gum and locust bean were added $(0.1 \% \mathrm{w} / \mathrm{v})$ for each and the solution was mixed using a magnetic stirrer. The solution was autoclaved at $121^{\circ} \mathrm{C}$ for $15 \mathrm{~min}$. Then, the solution was cooled to room temperature. Rosemary and oregano oil were added in concentration $2 \%(\mathrm{w} / \mathrm{v})$, as well as Ag NPs and $\mathrm{ZnO}$ NPs were added with different size. Earlier, rosemary and oregano oil were dissolved in $2 \mathrm{ml}$ of $95 \%$ ethanol. After the components of the film had been mixed, the solutions were poured into plastic Petri dishes. The films were dried overnight in a laminar flow cabinet under a flow of sterile air, at a temperature of $25^{\circ} \mathrm{C}$ and relative humidity of $45 \pm 5 \%$.

\section{Sample collection and preparation:}

Ready to eat (RTE) from turkey, was purchased from local market in Copenhagen City, Denmark. Samples were transported to the laboratory within 15 min., packed in separate insulated polystyrene boxes with ice. The meat was cut into $0.7 \mathrm{~mm}$ thickness of slices, and cut into sections $(5 \mathrm{~cm} \times 5$ $\mathrm{cm})$. The prior slices were treated with ultraviolet light (UV) for $15 \mathrm{~min}$. to reduce background microflora (Cutter and Siragusa 1994), and inoculated aseptically with overnight and diluted cultures of $S$. aureus and $L$. 
monocytogenes, to obtain approximately $6 \log _{10} \mathrm{CFU} / \mathrm{cm}^{2}$ on the surface. After inoculation, the samples were kept at room temperature for $20 \mathrm{~min}$. to allow for cell attachment. Inoculated meat surfaces were covered with pullulan films $(5 \mathrm{~cm} \times 5 \mathrm{~cm})$ containing either the essential oils or nanoparticles. Inoculated control samples were covered with pullulan film without any compounds. All samples were transferred individually into a standard vacuumpackaging bag (Ultravac Solutions LLC, Kansas City, Mo, USA) and vacuum sealed using a vacuum packaging machine (Ultravac 250 vacuum packaging machine; St. Louis, MO, USA). Vacuum packaged samples were held at $4^{\circ} \mathrm{C}$ for 2 weeks. Modified Oxford Agar (MOX, Difco) for L. monocytogenes, and Baird-Parker agar (BP, Difco) for $S$. aureus were used to determine the number of remaining cells. Resulting colonies were counted after 1-2 days of incubation at $37^{\circ} \mathrm{C}$, populations were converted to $\log _{10}$ (Trinetta et al. 2010).

\section{Storage conditions of pullulan films:}

Once the films had been formed, they were cut in rectangular strips of $25.4 \mathrm{~mm}$ in width and $75 \mathrm{~mm}$ length and were stored at different temperature $\left(4,25,37\right.$, and $\left.55^{\circ} \mathrm{C}\right)$. Films containing nanoparticles and essential oils were stored under the same conditions during 7 weeks in order to study the evolution of antimicrobial activity against $S$. aureus and L. monocytogenes. Samples were analyzed at $0,7,14,21,28,35,42$ and 49 days of storage.

\section{Antimicrobial activity of pullulan films:}

Antimicrobial activity test on films was carried out using the agar diffusion method according to (Chen et al. 1996). The zone of inhibition assay on solid media was used for determination of the antimicrobial effects of films against $S$. aureus and L.monocytogenes. The edible films were cut into 6-mmdiameter disks and then placed on Mueller Hinton agar (Merk, Darmstadt, Germany) plates, which had been previously seeded with $0.2 \mathrm{ml}$ of inoculums containing approximately $1 \times 10^{6} \mathrm{CFU} / \mathrm{ml}$. The plates were then incubated at $37^{\circ} \mathrm{C}$ for $24 \mathrm{~h}$. Then, the plates were examined for "zone of inhibition" of the film discs. The contact area was used to evaluate growth inhibition underneath the film disk in direct contact with target microorganisms in the agar. The area of the whole zone was calculated and then subtracted from the film disk area, and this difference area was reported as a zone of inhibition (Fernandez-Pan et al. 2012).

\section{Physical properties of films: \\ Film thickness:}

The thickness of each film sample was measured using a $0-25 \mathrm{~mm}$ manual micrometer (Mitutoyo Corporation, Kanagawa, Japan) with an accuracy of $0.001 \mathrm{~mm}$. Measurements were taken at 3 different points on each film sample and the average values were represented as the film thickness.

\section{Transparency test:}

The transparency of the film samples was measured according to the method described by Al-Hassan and Norziah (2012). A rectangular piece cut from each film sample was directly placed in a spectrophotometer cell. The 
absorbance was measured at $550 \mathrm{~nm}$ using digital UV/Vis-and Vis-Unicam Spectrophotometer (model 9423 Automatic Scanning Spectrophotometer). The measurements were carried out in triplicates for each film sample and the average values were calculated. The transparencies of the various films were calculated by dividing the absorbance by thickness $(\mathrm{mm})$.

\section{Film solubility:}

The solubility of film samples in water was measured by the method of Ghanbarzadeh et al. (2010) with some modifications. Film samples were cut into $3 \times 2 \mathrm{~cm}$ pieces and dried at $100^{\circ} \mathrm{C}$ for $12 \mathrm{~h}$. The dried film samples were dissolved in distilled water $(20 \mathrm{ml})$ under gentle agitation using a magnetic stirrer at room temperature. After the 3 min dissolution, the solution was taken out and dried in the oven at $105^{\circ} \mathrm{C}$ until the weight became stable. Before and after dissolution, the accurate weights of the dried film sample pieces were measured, and the weight difference was considered as soluble solids. The water solubility of film was calculated as a percentage based on the initial weight of the film. All the experiments were performed in triplicate.

\section{Oxygen permeability:}

Oxygen transmission rates through the pullulan films were determined, using an optical measuring system Optech ${ }^{\mathrm{TM}}$ Platinum $\mathrm{O}_{2}$ sensor device and disposable $\mathrm{O}_{2}$ sensor stickers from Mocon (Minneapolis, USA). The optical $\mathrm{O}_{2}$ sensor works on the principle of a phosphorescent dye that is incorporated in a polystyrene polymer membrane as adherent agent and for environmental protection. The Optech device uses LED technology to take measurement in $10 \mathrm{~s}$. For $\mathrm{O}_{2}$ measurements, the instrument need to be brought in an optical contact with the sensor (5-10 $\mathrm{mm}$ distance) to produce an $\mathrm{O}_{2}$ reading ( $\%$ of $\mathrm{O}_{2}$, compensated for temperature and pressure variation). The OxyDot-indicators were placed in the headspace of the samples using transparent adhesive. Windows-based software was used for the recording of measured parameters (oxygen concentration) and data storage (Molinaro et al. 2013)

\section{Statistical Analysis:}

The statistical analysis was carried out using ANOVA with one factor under significance level of 0.05 for the obtained results using SPSS and data were treated as a complete randomization design according to (Steel et al. 1997). The experiments were performed in triplicate, using three samples per treatment (Siragusa et al. 1999). Multiple comparisons were carried out applying LSD test. 


\section{RESULTS AND DISCUSSION}

\section{Appearance of pullulan films:}

Pullulan, excellent film-former, which has been used as an edible film with various flavors, herb extracts and spices (Diab et al. 2001). Its additional advantages are colorless, tasteless, odorless, transparent, flexible, highly impermeable to oil, heat-sealable, and with good oxygen barrier properties (Gounga et al. 2008). Aqueous solutions of pullulan may be used to form transparent, colorless and glossy films with relatively low oxygen permeability (Gounga et al. 2008). Pullulan can form homogeneous films, which is an important property for its use as a coating material in the food industry. However, there are very few reports in the literature regarding the application of pullulan edible films (Goksungur et al. 2005).

Figure 1 shows images of the surface of pullulan films with and without the addition of essential oils (EOs) and nanoparticles (NPs). The pullulan film produced without any additives was completely transparent, smooth, and glossy. No changes were observed in the films containing oregano $2 \%$, rosemary $2 \%, \mathrm{ZnO}$ (NPs) $110 \mathrm{~nm}$ and Ag (NPs) $100 \mathrm{~nm}$, compared with the control film. The addition of essential oils to the film resulted in intensive odor of oregano and rosemary. These results are in agreement with those reported by Gniewosz and Synowiec (2011)
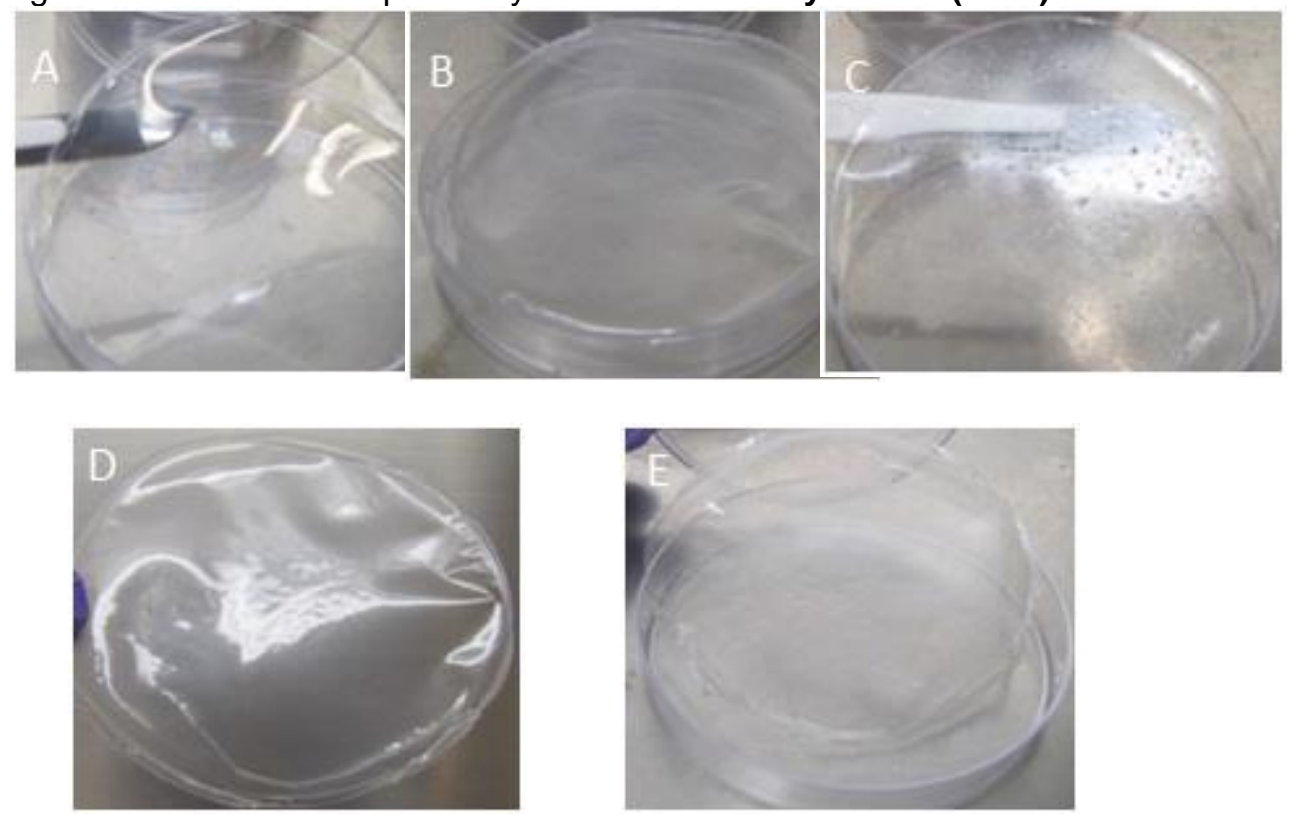

Figure (1) Images of the surfaces of the pullulan films: (A) without the addition; (B) with the addition of $2 \%$ oregano; (C) with the addition of $2 \%$ rosemary; (D) with Ag (NPs) $100 \mathrm{~nm}$; and (E) with $\mathrm{ZnO}$ (NPs) $110 \mathrm{~nm}$. 


\section{Physical properties of pullulan films: Thickness:}

Thickness one of the most important parameters, related to transparency, water vapor permeability, and mechanical properties of the films. The thickness of the pure pullulan film, and pullulan incorporated with essential oils and nanoparticles are shown in Table (1). Changes in film thickness were observed with the addition of essential oil into the pullulan filmforming solutions. There are high thicknesses in pullulan-containing essential oil compared with control. However, no significant differences between films incorporated nanoparticles with control. Attributed an increase of thickness in pullulan essential oil to properties of oil with polysaccharides, while the nanoparticles film were decreased due small molecular and matched with polysaccharide structure. These results are generally in agreement with those of Maizura et al. (2007).

Transparency:

Transparency is an important index in terms of general appearance and consumer acceptance. The transparency of the various films is summarized in Table (1). Pullulan edible film without essential oil incorporation appeared clear and transparent. Addition of oregano and rosemary essential oil affected the appearance of edible film in both color and transparency. The color tended to yellowish as indicated by the increase of optical density. However, addition of nanoparticles hasn't affected the appearance of edible film, so there were no significant differences. These results are in agreement with those reported by Pranoto (2005) and Pinto (2013).

\section{Water solubility:}

Film solubility is an important factor that determines biodegradability of films when used as packaging wrap (Gnanasambandam et al. 1997). Table (1) shows that percent water solubility was higher for pure pullulan film $(100 \%)$. Incorporation of both rosemary and oregano essential oils in pullulan film decreased the solubility ranged from 99.15 to $99.18 \%$, respectively. Also, the pullulan film incorporated $\mathrm{Ag}$ and $\mathrm{ZnO}$ nanoparticles decreased the solubility ranged from 98.65 to $98.94 \%$, respectively. Attributed of decreased of water solubility to essential oils and nanoparticles scarce of soluble in water. These results are in agreement with those reported by Pranoto (2005) and Rojas-Graü (2006). Although a lower solubility of edible films is required during storage, a high solubility of edible film will be advantageous during cooking food products coated with edible films (Laohakunjit and Noomhorm 2004).

\section{Oxygen permeability:}

Data in Table (1) show the percentage of oxygen permeability in pure pullulan film and film's incorporation of essential oils and nanoparticles. Indicated that films containing essential oils and nanoparticles exhibit relatively poor oxygen barrier properties. Oil chemical nature plays a major role in the barrier properties of edible films. Similar results were found by Rojas-Graü et al. (2006) who showed lower oxygen permeability was 
observed in films that contained oregano, lemon grass and cinnamon oils than in those that contained its antibacterial compounds carvacrol, citral and cinnamaldehyde, respectively.

Table (1):Physical properties of pullulan edible films incorporated with essential oils and nanoparticles.

\begin{tabular}{|l|c|c|c|c|c|}
\hline \multirow{2}{*}{ Properties } & \multicolumn{5}{|c|}{ Antimicrobial pulluan films } \\
\cline { 2 - 6 } & Control & $\begin{array}{c}\text { Oregano } \\
\text { oil } \\
\mathbf{2 \%}\end{array}$ & $\begin{array}{c}\text { Rosemary } \\
\text { oil } \\
\mathbf{2 \%}\end{array}$ & $\begin{array}{c}\mathbf{A g}(\mathbf{N P s}) \\
\mathbf{1 0 0} \mathbf{~ n m}\end{array}$ & $\begin{array}{c}\text { ZnO (NPs) } \\
\mathbf{1 1 0} \mathbf{~ n m}\end{array}$ \\
\hline Thickness (mm) & 0.108 & 0.112 & 0.111 & 0.108 & 0.109 \\
& \pm 0.001 & \pm 0.001 & \pm 0.001 & \pm 0.001 & \pm 0.001 \\
\hline Transparency & 0.768 & 0.857 & 0.892 & 0.809 & 0.789 \\
& \pm 0.01 & \pm 0.02 & \pm 0.01 & \pm 0.02 & \pm 0.02 \\
\hline Water soluble (\%) & 100 & 99.18 & 99.15 & 98.65 & 98.94 \\
Oxygen permeability (\%) & \pm 0 & \pm 0.02 & \pm 0.02 & \pm 0.27 & \pm 0.28 \\
\hline
\end{tabular}

* Mean of triplicate determinations $\pm \mathrm{SE}$.

Effect of storage temperature on antimicrobial activity of pullulan films:

The stability of pullulan films incorporated essential oils and nanoparticles at $\left(4,25,37\right.$ and $\left.55^{\circ} \mathrm{C}\right)$ against $S$. aureus and $L$. monocytogenes during seven weeks was investigated. As shown in Fig. (2 and 3 ), it could be observed that inhibition zone of pullulan film incorporated oregano oil was $32 \mathrm{~mm}$ against $S$. aureus in time zero, while after seven weeks of storage were, $30.33,28,0$ and $0 \mathrm{~mm}$ at $4,25,37$ and $55^{\circ} \mathrm{C}$, respectively. The inhibition zone of pullulan incorporated oregano oil in time zero is $29.33 \mathrm{~mm}$ against $L$. monocytogenes, while after seven weeks were, $27.83,25.5,0$ and $0 \mathrm{~mm}$ at $4,25,37$ and $55^{\circ} \mathrm{C}$, respectively. Pullulan films incorporated oregano oil did not change during storage at 4 and $25^{\circ} \mathrm{C}$, against $S$. aureus and $L$. monocytogenes while, there are changes during storage at 37 and $55^{\circ} \mathrm{C}$. The antimicrobial effect of oregano oil is attributed to the relatively high concentration of caracole and p-cymene compounds, which causes depletes the intracellular ATP pool, changes the membrane potential, and increases the permeability of the cytoplasmic membrane to potassium ions and proteins (Ultee et al. 2002). Low temperature kept the carvacrol compound from evaporating than high temperature. These obtained results are in general agreement with previously those reported by Seydim and Sarikus (2006); Du et al. (2009) and Zhang et al. (2009).

Results in Fig. (4 and 5) show that inhibition zone of pullulan film incorporated rosemary oil was $18.67 \mathrm{~mm}$ against $S$. aureus in time zero, while after seven weeks were $17.17,13.5,0$ and $0 \mathrm{~mm}$ at $4,25,37$ and $55^{\circ} \mathrm{C}$, respectively. The inhibition zone of pullulan incorporated rosemary oil in time zero is $22.17 \mathrm{~mm}$ against $L$. monocytogenes, while after seven weeks were 19.83, 17.17, 0 and $0 \mathrm{~mm}$ at $4,25,37$ and $55^{\circ} \mathrm{C}$, respectively. Pullulan film incorporated rosemary oil was more effective against $S$. aureus and L.monocytogenes when stored at 4 and $25^{\circ} \mathrm{C}$. However, the effectiveness during stored at 37 and $55^{\circ} \mathrm{C}$. The antimicrobial effect of rosemary oil is due to 
cineole and $\alpha$-pinene compounds, which causes thickening and disruption of the cell wall together with increased roughness and lack of cytoplasm (Nowak et al. 2012).

The low temperature maintain of the major effective compounds rosemary oil (cineole and $\alpha$-pinene) from evaporating when compared to high temperature. These results are in harmony with those previously reported by Abdollahi et al. (2012). Gram-positive bacteria are found to be more sensitive to the essential oils effects (Burt 2004). Fig. (6 and 7) illustrate that the effect of storage temperature on antimicrobial activity of pullulan edible film incorporated silver nanoparticles $100 \mathrm{~nm}$ against $S$. aureus and $L$. monocytogenes.

The inhibition zone diameters yielded by pullulan based edible film disks with silver nanoparticles $100 \mathrm{~nm}$ was $30.33 \mathrm{~mm}$ against S.aureus in time zero, while after seven weeks of storage were 28.67, 26, 15.5 and $0 \mathrm{~mm}$ at 4 , 25,37 and $55^{\circ} \mathrm{C}$, respectively. Also, observed that inhibition zone is $22.17 \mathrm{~mm}$ against $L$. monocytogenes in time zero, while after seven weeks were19.83, $17,13.83$ and $0 \mathrm{~mm}$ at $4,25,37$ and $55^{\circ} \mathrm{C}$, respectively. The pullulan films incorporated silver nanoparticles $100 \mathrm{~nm}$ was stable during storage at 4 and $25{ }^{\circ} \mathrm{C}$ as antibacterial, against $S$. aureus and L. monocytogenes, but, not stabile during storage at 37 and $55^{\circ} \mathrm{C}$. The low temperature kept silver nanoparticles than high temperature. These obtained results in general agreement with those previously reported by Fayaz et al. (2009).

As shown in Fig. (8 and 9) the inhibition zone diameters for zinc oxide nanoparticles against $S$. aureus in time zero was $18.33 \mathrm{~mm}$, while after seven weeks were $16.83,13.5,9.17$ and $0 \mathrm{~mm}$ at $4,25,37$ and $55^{\circ} \mathrm{C}$, respectively. As same time the inhibition zone of zinc oxide nanoparticles against $L$. monocytogenes in time zero was $17.67 \mathrm{~mm}$, while after seven weeks were 15.67, 12.5, 0 and $0 \mathrm{~mm}$ at $4,25,37$ and $55^{\circ} \mathrm{C}$, respectively. The pullulan films incorporated zinc oxide nanoparticles $110 \mathrm{~nm}$ more effective during storage at 4 and $25^{\circ} \mathrm{C}$, against $S$. aureus and L. monocytogenes. However, this films effectiveness during storage at 37 and $55^{\circ} \mathrm{C}$. The low temperature kept zinc oxide nanoparticles than high temperature. These obtained results in general agreement with those previously reported with Bajpai et al. (2012).

From above mentioned results, it could be concluded that optimum conditions for storage pullulan edible films incorporated essential oils (EOs) and/or nanoparticles (NPs), in order to work as active packaging were 4 and $25^{\circ} \mathrm{C}$.

Inhibition of pathogenic microorganisms in turkey deli meat by essential oils and nanoparticles-containing pullulan films:

In the last phase of this study, pullulan films containing oregano $2 \%$, rosemary 2\%, Ag (NPs) $100 \mathrm{~nm}$ and ZnO (NPs) $110 \mathrm{~nm}$ were evaluated for their long-term antimicrobial effectiveness against $L$. monocytogens and $S$. aureus when applied in turkey deli meat, under vacuum packaged, and stored at $4{ }^{\circ} \mathrm{C}$ for up to 2 weeks. Data in Table (2) present effect of pullulan films without and with the addition of different types of antimicrobials against $L$. 
monocytogens on turkey deli meat. Therefore, observed that progressively grew $\left(1 \log _{10} \mathrm{CFU} / \mathrm{g}\right)$ in samples treated pullulan film (control) but continually during the 2 weeks of refrigerated vacuum packaged storage. Conversely, the samples packaged with essential oils and nanoparticles containing pullulan films, and demonstrated a decrease of approximately 1 log unit in populations of $L$. monocytogens after $24 \mathrm{~h}$. This 1 log reduction observed between control and treated samples remained constant until the end of the challenge study. As shown in Table (3) $S$. aureus was sensitive organism tested in these experiments, population reductions on turkey deli meat surfaces which treated with the essential oils and nanoparticles incroprated in pullulan films were approximately 2-3 $\log _{10} \mathrm{CFU} / \mathrm{g}$, as compared with the control. 
J. Food and Dairy Sci., Mansoura Univ., Vol. 4 (11), November, 2013

Table (2): Effect of antimicrobial pullulan films on Listeria monocytogenes in turkey deli meat.

\begin{tabular}{l|c|c|c|c|c|}
\hline \multirow{2}{*}{$\begin{array}{l}\text { Additives of } \\
\text { pullulan films }\end{array}$} & Zero & $\mathbf{1}$ & $\mathbf{2}$ & $\mathbf{7}$ & $\mathbf{1 4}$ \\
\cline { 2 - 6 } Control & $6.01 \pm 0.04^{\mathrm{aA}}$ & $6.05 \pm 0.02^{\mathrm{cA}}$ & $6.23 \pm 0.14^{\mathrm{cA}}$ & $7.69 \pm 0.02^{\mathrm{bB}}$ & $7.53 \pm 0.03^{\mathrm{cB}}$ \\
\hline Rosemary 2\% & $6.25 \pm 0.32^{\mathrm{aE}}$ & $2.93 \pm 0.03^{\mathrm{aD}}$ & $2.03 \pm 0.13^{\mathrm{aB}}$ & $2.4 \pm 0.07^{\mathrm{aC}}$ & $1.06 \pm 0.53^{\mathrm{bA}}$ \\
\hline Oregano $2 \%$ & $6 \pm 0.02^{\mathrm{aD}}$ & $3.62 \pm 0.22^{\mathrm{bC}}$ & $2.56 \pm 0.05^{\mathrm{bB}}$ & $2.68 \pm 0.03^{\mathrm{aB}}$ & $1.68 \pm 0.21^{\mathrm{bA}}$ \\
\hline $\mathrm{Ag}(\mathrm{NPs}) 100 \mathrm{~nm}$ & $5.98 \pm 0.02^{\mathrm{aD}}$ & $3.03 \pm 0.05^{\mathrm{aC}}$ & $2.65 \pm 0.06^{\mathrm{bB}}$ & $2.36 \pm 0.07^{\mathrm{aB}}$ & $0.43 \pm 0.43^{\mathrm{aA}}$ \\
\hline $\mathrm{ZnO}(\mathrm{NPs}) 110 \mathrm{~nm}$ & $5.95 \pm 0.01^{\mathrm{aE}}$ & $2.8 \pm 0.03^{\mathrm{aD}}$ & $2.23 \pm 0.16^{\mathrm{aB}}$ & $2.54 \pm 0.02^{\mathrm{aC}}$ & $0.53 \pm 0.53^{\mathrm{aA}}$ \\
\hline
\end{tabular}
* Mean of triplicate determinations $\pm \mathrm{SE}$.
Data in the table are log number of bacteria
Mean values in the same column (as a small letter) or row (as a capital letter) with the
same letter are not significant different at 0.05 level.


Table (3): Effect of antimicrobial pullulan films on Staphylococcus aureus in turkey deli meat.

\begin{tabular}{|c|c|c|c|c|c|}
\hline \multirow{2}{*}{$\begin{array}{l}\text { Additives of } \\
\text { pullulan films }\end{array}$} & \multicolumn{5}{|c|}{ Storage periods (days) } \\
\hline & Zero & 1 & 2 & 7 & 14 \\
\hline Control & $5.99 \pm 0.02^{\star 2 A}$ & $6.18 \pm 0.14^{\mathrm{CA}}$ & $6.39 \pm 0.15^{\mathrm{bA}}$ & $6.38 \pm 0.29^{\mathrm{CA}}$ & $6.76 \pm 0.04^{\mathrm{CB}}$ \\
\hline Rosemary 2\% & $6.25 \pm 0.36^{\mathrm{bD}}$ & $2.54 \pm 0.05^{\mathrm{bC}}$ & $2 \pm 0.13^{\mathrm{aB}}$ & $2.63 \pm 0.02^{\mathrm{bA}}$ & $0.43 \pm 0.43^{\mathrm{aA}}$ \\
\hline Oregano $2 \%$ & $5.98 \pm 0.02^{\mathrm{aD}}$ & $2.68 \pm 0.07^{\mathrm{aC}}$ & $2.05 \pm 0.15^{\mathrm{aB}}$ & $2.68 \pm 0.04^{\mathrm{bA}}$ & $1.03 \pm 0.51^{\mathrm{bA}}$ \\
\hline $\mathrm{Ag}(\mathrm{NPs}) 100 \mathrm{~nm}$ & $5.91 \pm 0.01^{\mathrm{aD}}$ & $1.91 \pm 0.08^{\mathrm{aC}}$ & $1.58 \pm 0.07^{\mathrm{aB}}$ & $1.59 \pm 0.06^{\mathrm{aB}}$ & $0 \pm 0^{\mathrm{aA}}$ \\
\hline $\mathrm{ZnO}(\mathrm{NPs}) 110 \mathrm{~nm}$ & $5.94 \pm 0.01^{\mathrm{aE}}$ & $2.07 \pm 0.12^{\mathrm{bC}}$ & $1.56 \pm 0.14^{\mathrm{aB}}$ & $2.4 \pm 0.05^{\mathrm{bD}}$ & $0.49 \pm 0.49^{\mathrm{aA}}$ \\
\hline
\end{tabular}

These results clearly demonstrate that essential oils (EOs) and nanoparticles (NPs) can migrate from the biopolymer into the food and inhibit the pathogen over 2 weeks of refrigerated storage. The use of packaging films containing antimicrobials appears to be a promising delivery method of the antimicrobial compound, even if the release of the active agent is limited to the surface of the foods (Quintavalle and Vicini 2002). Oussalah et al. (2006) stated that alginate and milk protein films containing $1.0 \%$ oregano oil were effective against $E$. coli 0157: $\mathrm{H} 7$ S.Typhimurium, L. monocytogens and S. aureus inoculated on beef. Rhim et al. (2006) found that chitosan-based nanocomposite films incorporates sliver nanoparticles were effective against foodborne pathogens. Moreover, a pullulan packaging system requires less amount of antimicrobial, exhibits longer antimicrobial activity and may permit controlled migration of the molecule from film to the food matrix. This approach not only allows for initial inhibition of undesirable microorganisms, but also allows for release and residual activity over time, especially during transportation, storage and distribution. It is important to note that direct addition of antimicrobials could result in some loss of activity, because of cross-reactions with food components, such as lipids or proteins (Quintavalle and Vicini 2002).

These experiments clearly demonstrated the antimicrobial activity of the pullulan film containing $\mathrm{Ag}$ (NPs), $\mathrm{ZnO}$ (NPs), oregano and rosemary essential oils, its effect against pathogen microorganisms associated with raw and processed meats.

\section{CONCLUSION}

The results of the present study concluded that Ag (NPs), ZnO (NPs), rosemary and oregano containing pullulan films were inactivated pathogen microorganisms especially $L$. monocytogens and $S$. aureus that contribute to meat spoilage. The antimicrobial activity of Ag NPs and oregano essential oil in pullulan edible films against both pathogens was significantly greater than the activities of ZnO NPs and rosemary oil, respectively. There was no effect on the physical properties of the edible film formed as observed. The optimum condition for storage pullulan edible films incorporated (NPs) and/or (EOs), in order to work as active packaging was 4 and $25^{\circ} \mathrm{C}$. Antibacterial pullulan 
edible film incorporating NPs and EOs provides a novel way to enhance the safety and shelf-life in food systems. Therefore, are promising and have good potential in many food applications.

\section{ACKNOWLEDGMENTS}

The authors would like to express their sincere gratitude and appreciation for the financial support from the Danish Agency for Universities and Internationalization. The authors want to thank (Department MicroNanotech, Technical University of Denmark, University, DTU) for hosting this research project.

\section{REFERENCES}

Abdollahi, M., Rezaei, M. and Farzi, G. (2012). A novel active bionanocomposite film incorporating rosemary essential oil and nanoclay into chitosan. Journal of Food Engineering 111, 343-350.

Al-Hassan, A. A. and Norziah, M. H. (2012). Starch-gelatin edible films: Water vapor permeability and mechanical properties as affected by plasticizer. Food Hydrocolloids 26, 108-117.

Anker, M., Stading, M. and Hermansson, A.M. (2001). Aging of whey protein films and the effect on mechanical and barrier properties. J. Agric. Food. Chem. 49(2): 989-995.

Appendini, P. and Hotchkiss, J.H. (2002). Review of antimicrobial food packaging. Innovative Food Science \& Emerging Technologies 3, 113126.

Bajpai, S.K., Chand, N. and Chaurasia, V. (2012). Nano zinc oxide-loaded calcium alginate films with potential antibacterial properties. Food Bioprocess Technol. 5, 1871-1881.

Burt, S. (2004). Essential oils: their antibacterial proprieties and potential application in food. Journal of Applied Microbiology 94, 223-253.

Chen, M.C., Yeh, G.H.C. and Chiang, B.H. (1996). Antimicrobial and physicochemical properties of methylcellulose and chitosan films containing a preservative. J. Food Process. Preserv. 20, 279-390.

Chen, X. and Schluesener, H.J. (2008). Nanosilver: a nanoproduct in medical application.Toxicology Letters 176, 1-12.

Cheng, K., Demirci, A. and Catchmark, J.M. (2011). Pullulan: biosynthesis, production, and applications. Appl. Microbiol. Biotechnol. 92, 29-44.

Cutter, C.N. and Siragusa, G.R. (1994). Efficacy of organic acids against Escherichia coli 0157:H7 attached to beef carcass tissue using a pilot scale model carcass washer. J. Food Protect 57: 97-103.

Damm, C., Munstedt, H. and Rosch, A. (2008). The antimicrobial efficacy of polyamide 6/silver-nano- and microcomposites. Mater. Chem. Phys. $108,61-66$. 
Diab, T., Biliaderis, C.G., Gerasopoulos, D. and Sfakiotakis, E. (2001). Physicochemical properties and application of pullulan edible film and coatings in fruit preservation. J. Food Sci. Agric. 81, 988-1000.

Du, W.X., Olsen C.W., Avena-Bustillos, R.J., McHugh, T.H., Levin, C.E. and Friedman, M. (2009). Effects of allspice, cinnamon and clove bud essential oils in apple films on antimicrobial activities against Escherichia coli 0157:H7, Salmonella enterica, and Listeria monocytogenes. Journal of Food Science 74(7): M372-M378.

Fayaz, A.M., Balaji, K., Girilal, M., Kalaichelvan, P. T. and Venkatesan, R. (2009). Mycobased Synthesis of Silver Nanoparticles and Their Incorporation into Sodium Alginate Films for Vegetable and Fruit Preservation. J. Agric. Food Chem. 57, 6246-6252.

Fernandez-Pan, I., Royo, M. and Mate, J.I. (2012). Antimicrobial activity of whey protein isolate edible films with essential oils against food spoilers and foodborne pathogens. Journal of Food Science 77, M 383-M390.

Friedman, M., Henika, P.R. and Mandrell, R.E. (2002). Bactericidal activities of plant essential oils and some of their isolated constituents against Campylobacter jejuni, Escherichia coli, Listeria monocytogenes, and Salmonella enterica. Journal of Food Protection 65, 1545-1560.

Ghanbarzadeh, B., Almasi, H. and Entezami, A. A. (2010). Physical properties of edible modified starch/carboxymethyl cellulose films. Innovative Food Science and Emerging Technologies 11, 697-702.

Gnanasambandam, R., Hettiarachchy, N. S. and Coleman, M. (1997). Mechanical and barrier properties of rice bran films. Journal of Food Science 62, 395-398.

Gniewosz, M. and Synowiec, A. (2011). Antibacterial activity of pullulan films containing thymol. Flavour and Fragance Journal 26, 289-395.

Goksungur, Y., Dagbalı, U.A. and Guvenc, U. (2005). Optimization of pullulan production from synthetic medium by Aureobasidium pullulans in a stirred tank reactor by response surface methodology. Journal of Chemical Technology and Biotechnology 80:819-827.

Gounga, M.E., Xu, S.Y., Wang, Z. and Yang, W.G. (2008). Effect of whey proteinisolate-pullulan edible coating on the quality and shelf life of freshly roasted and freeze-dried Chinese chestnut. Journal of Food Science 73,155-161.

Jones, N., Ray, B., Ranjit, K. T. and Manna, A. C. (2007). Antibacterial activity of $\mathrm{ZnO}$ nanoparticle suspensions on a broad spectrum of microorganism. FEMS Microbiology Letters 279, 71-76.

Kandemir, N., Yemenicioglu, A., Mecitoglu, C., Elmaci, Z. S., Arslanoglu, A. and Oksungur, Y. (2005). Production of antimicrobial films by incorporation of partially purified lysozyme into biodegradable films of crude exopolysaccharides obtained from Aureobasidium pullulans fermentation. Food Technology and Biotechnology 43, 343-350.

Kim, S.Y., Kang, D.H., Kim, J.K., Ha, Y.G., Hwang, J.Y., Kim, T. and Lee, S.H. (2011). Antimicrobial activity of plant extracts against Salmonella Typhimurium, Escherichia coli O157:H7, and Listeria monocytogenes on fresh lettuce. Journal of Food Science 76, M41-M46. 
Kumari, P.T.S., Abhilash, S., Manzoor, K., Nair, S.V., Tamura, H. and Jayakumar, R. (2010). Preparation and characterization of novel bchitin/nanosilver composite scaffolds for wound dressing applications. Carbohydrate Polymers 80, 761-767.

Laohakunjit, N. and Noomhorm, A. (2004). Effect of plasticizers on mechanical and barrier properties of rice starch film. Starch/Starke 56, 348-356.

Lu, Y., Tighzert, L., Berzin, F. and Rondot, S. (2005). Innovative plasticized starch films modified with waterborne polyurethane from renowable sources. Carbohydrate Polymers 61, 174-182.

Maizura, M., Fazilah, A., Norziah, M. H. and Karim, A. A. (2007). Antibacterial activity and mechanical properties of partially hydrolyzed sago starchalginate edible film containing lemongrass oil. Journal of Food Science 72(6): C324-C330.

Marcos, B., Aymerich, T., Garriga, M. and Arnau, J. (2013). Active packaging containing nisin and high pressure processing as post-processing listericidal treatments for convenience fermented sausages. Food Control 30, 325-330.

Micard, V., Belamri, R., Morel, M.H. and Guilbert, S. (2000). Properties of chemically and physically treated wheat gluten films. J. Agric. Food Chem. 48(7): 2948-2953.

Molinaro, S., Romero, M.C., Boaro, M., Sensidoni, A., Lagazio, C., Morris, M. and Kerry, J. (2013). Effect of nanoclay-type and PLA optical purity on the characteristics of PLA-based nanocomposite films. Journal of Food Engineering 117, 113-123.

Nafchi, A.M., Alias, A., Mahmud, S. and Robal, M. (2013). Antimicrobial, rheological, and physicochemical properties of sago starch films filled with nanorod-rich zinc oxide. Journal of Food Engineering 113, 511519.

Nowak, A., Kalemba, D., Krala, L., Piotrowsk, M. and Czyzowska, A. (2012). The effects of thyme (Thymus vulgaris) and rosemary (Rosmarinus officinalis) essential oils on Brochothrix thermosphacta and on the shelf life of beef packaged in high-oxygen modified atmosphere. Food Microbiology 32, 212-216.

Olasupo, N.A., Fitzgerald, D.J., Gasson, M.J. and Narbad, A. (2003). Activity of natural antimicrobial compounds against Escherichia coli and Salmonella enteric serovar Typhimurium. Letters in Applied Microbiology 37, 448-451.

Oses, J., Fernandez-Pan, I., Mendoza, M. and Mate, J.I. (2009). Stability of the mechanical properties of edible films based on whey protein isolate during storage at different relative humidity. Food Hydrocolloids 23, 125-131.

Oussalah, M., Caillet, S., Salmieri, S., Saucier, L. and Lacroix, M. (2006). Antimicrobial effects of alginate-based film containing essential oils for the preservation of whole beef muscle. Journal of Food Protection 69, 2364-2369. 
Pinto, R.J.B., Almeid, A., Fernandes, S.C.M., Freire, C.S.R., Silvestre, A.J.D., Neto, C.P. and Trindade, T. (2013). Antifungal activity of transparent nanocomposite thin films of pullulan and silver against Aspergillus niger. Colloids and Surfaces B: Biointerfaces 103, 143-148.

Pranoto, Y., Salokhe, V.M. and Rakshit, S.K. (2005). Physical and antibacterial properties of alginate-based edible film incorporated with garlic oil. Food Research International 38, 267-272.

Quintavalla, S. and Vincini, L. (2002). Antimicrobial food packaging in meat industry. Meat Science 62, 373-380.

Rhim, J., Hong, S., Park, H. and Perry K.W.N. (2006). Preparation and characterization of chitosan-based nanocomposite films with antimicrobial activity. J. Agric. Food Chem. 54, 5814-5822.

Rojas-Graü, M.A., Avena-Bustillos, R.J., Friedman, M., Henika, P.R., MartinBelloso, O. and Mchugh, T.H. (2006). Mechanical, barrier, and antimicrobial properties of apple puree edible films containing plant essential oils. Journal of Agricultural and Food Chemistry 54, 92629267.

Seydim, A.C. and Sarikus, G. (2006). Antimicrobial activity of whey protein based edible films incorporated with oregano, rosemary and garlic essential oils. Food Research International 39, 639-644.

Siragusa, G.R., Cutter, C.N. and Willet, J.L. (1999). Incorporation of bacteriocin in plastic retains activity and inhibits surface growth of bacteria on meat. Food Microbiol. 16, 229-235.

Steel, R., Torrie, J. and Dickey, D. (1997). Principles and Procedures of Statistics: A Biometrical Approach, $3^{\text {rd }}$ ed, McGraw-Hill, New York, NY.

Suppakul, P., Miltz, J., Sonneveld, K. and Bigger, S.W. (2003). Active packaging technologies with an emphasis on antimicrobial packaging and its applications. Journal of Food Science 68, 408-420.

Tharanathan, R. N. (2003). Biodegradable films and composite coatings: past, present and future. Trends in Food Science and Technology 14, 71-78.

Trinetta, V., Floros, J.D. and Cutter, C.N. (2010). Sakacin A-containing pullulan film: An active packaging system to control epidemic clones of listeria monocytogenes in ready-to-eat foods. Journal of Food Safety 30, 366-381.

Ultee, A., Bennik, M.H. and Moezelaar, R. (2002). The phenolic hydroxyl group of carvacrol is essential for action against the foodborne pathogen Bacillus cereus. Applied and Environmental Microbiology 68, 1561-1568.

Yadav, A., Prasad, V., Kathe, A. A., Raj, S., Yadav, D. and Sundarmoorthy, C. (2006). Functional finishing in cotton fabrics using zinc oxide nanoparticles. Bulletin of Material Science 29(6), 641-645.

Zhang, H., Kong, B., Xiong, Y.L. and Sun, X. (2009). Antimicrobial activities of spice extracts against pathogenic and spoilage bacteria in modified atmosphere packaged fresh pork and vacuum packaged ham slices stored at $4^{\circ} \mathrm{C}$. Meat Science 81, 686-692. 


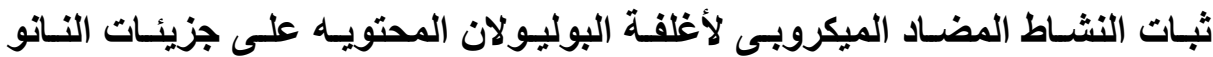

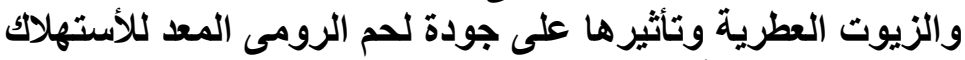

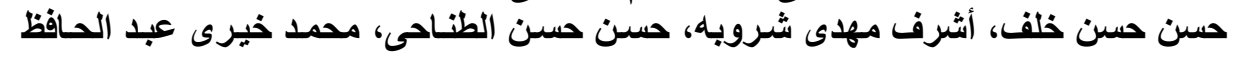

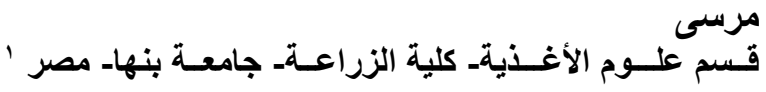

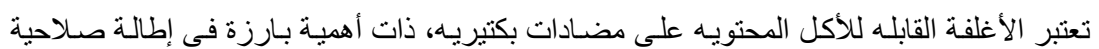

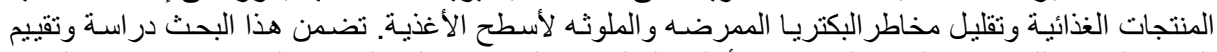

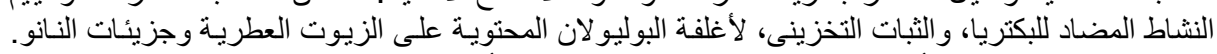

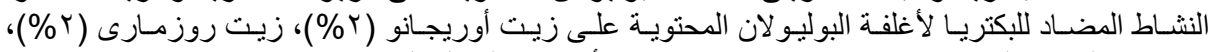

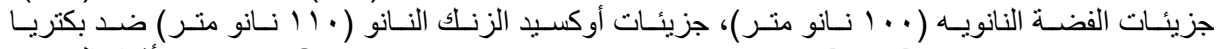
Staphylococcus aureus and Listeria monocytogenes

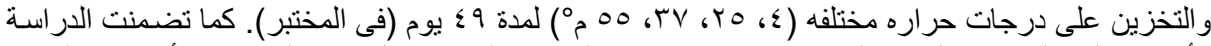

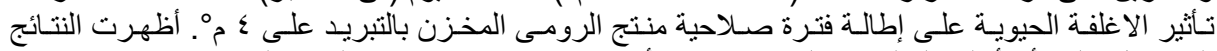

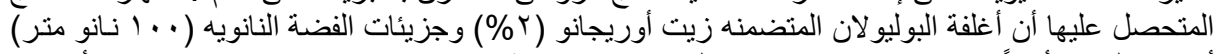

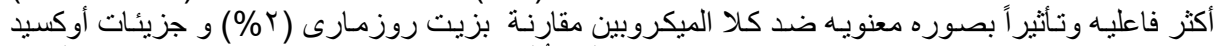

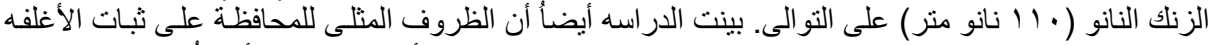

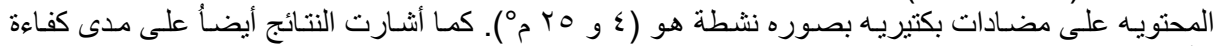

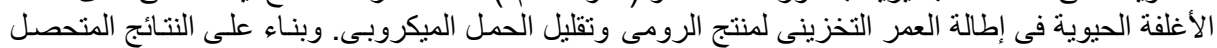
عليها نوصى بإستخدم ونطبيق الأغلفه المحتويه الزيوت العطرية وجنية العزيئات النانو فى مختلف الأغذية.

كلية الزراعة - جامعة المنصورة كلية الزراعة - جامعة بنها

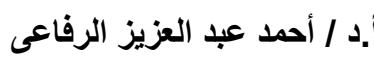

أ.د / حمدى عبد اللطيف المنسى

قام بتحكيم البحث 


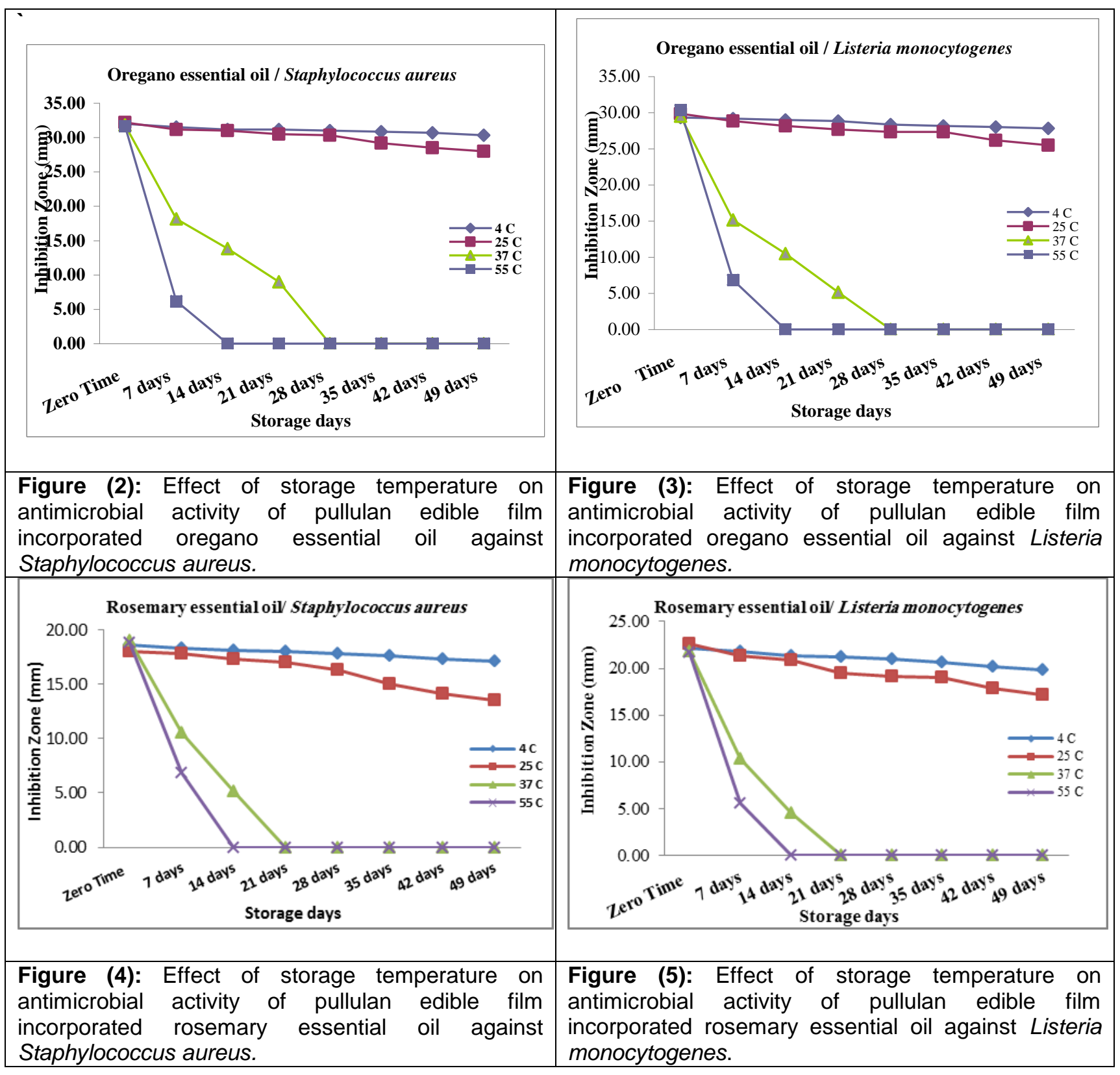




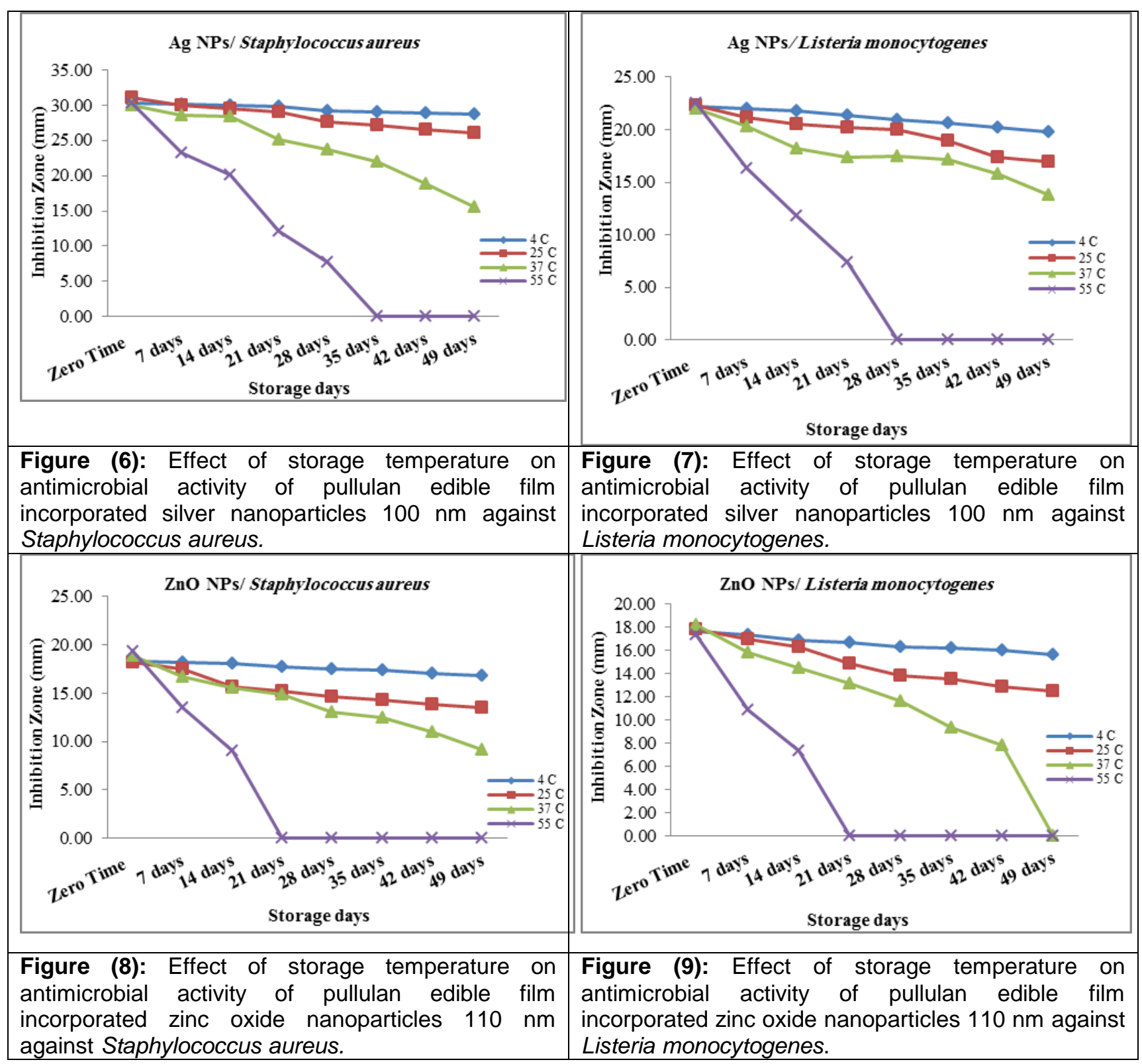

